\title{
Special challenges for drug adherence following generic substitution in Pakistani immigrants living in Norway
}

\author{
Helle Håkonsen • Else-Lydia Toverud
}

Received: 9 August 2010 / Accepted: 16 November 2010 / Published online: 16 December 2010

(C) The Author(s) 2010. This article is published with open access at Springerlink.com

\begin{abstract}
Purpose This study aims to explore how long-term drug users with a Pakistani background living in Oslo (Norway) perceive generic substitution and how generic substitution influences drug adherence in this population.

Methods Personal interviews using a semi-structured questionnaire were carried out with 83 Pakistani immigrants (aged 40-80 years) who were using antihypertensives, antidiabetics, and/or cholesterol-lowering drugs.

Results In all, $73 \%$ of the participants were using generic drugs at the time of the interview. Of these, $10 \%$ were erroneously using two equivalent generics at the same time. One quarter of the participants were of the opinion that cheaper generic drugs were counterfeit drugs. Two thirds had accepted generic substitution in the pharmacy whereas the remaining participants had either opposed or were unaware of the substitution. Of those who had accepted substitution, $27 \%$ claimed that the effect of the new drug was poorer and $20 \%$ reported more side-effects. Generic substitution had resulted in concerns about the therapy in $41 \%$ of the patients, and $26 \%$ thought it had become more demanding to keep track of their medication. Poor adherence tended to be most common among patients who were not fluent in Norwegian, patients who had concerns about medicine use, and patients who had accepted generic substitution in the pharmacy.

Conclusion This study shows that generic substitution may have a negative effect on drug adherence in Pakistani immigrants in Oslo (Norway) because of concerns and misconceptions, including confusion with regard to counterfeit drugs. Problems result primarily from inadequate
\end{abstract}

H. Håkonsen $(\varangle) \cdot$ E.-L. Toverud

School of Pharmacy, University of Oslo,

Oslo, Norway

e-mail: helle.hakonsen@farmasi.uio.no information caused by language barriers but also from culturally conditioned views on encounters with the health care system.

Keywords Adherence - Compliance - Cost containment . Generic drugs · Generic substitution · Pakistani immigrants

\section{Introduction}

Due to their low cost profile, there is a strong global focus on generic drugs. Increased use of these drugs has been promoted by governments as a means of combatting the growth in the public pharmaceutical budget, and most Western countries have implemented generic prescribing and/or generic substitution in order to achieve this [1-6]. In low-income countries, the availability of cheaper generics is pivotal to access to affordable medication for many patients [7]. It is estimated that these drugs account for the largest shares of total sales in the poorest parts of the world [8].

Since the late 1960s immigration from Pakistan to Norway has been considerable. Currently, Pakistani immigrants constitute the largest foreign ethnicity group in the capital city, Oslo [9]. There are large contrasts between the two countries. Norway has a comprehensive reimbursement scheme that provides the inhabitants with quality-assured pharmaceuticals. The patients have to cover a 38\% copayment, restricted upwards to $€ 230$ a year. In all, $70 \%$ of pharmaceutical expenditure is reimbursed by the government [10]. In Pakistan, on the other hand, more than the same amount is out-of-pocket expenses [8]. Whereas the Norwegian pharmaceutical market is subject to strict control, Pakistan governments struggle with unresolved regulatory issues with respect to pharmaceutical quality [11]. However, the governments of both countries are strong advocates of generic drug use. 
In Norway, generic substitution by pharmacy employees has been allowed since 2001 [3]. This implies that the pharmacies are obliged to stock less expensive generics and offer them to the patients unless the price difference is insignificant. As for the approval and the distribution of drugs in general, the generic market segment is strictly regulated both clinically (involving bioequivalence testing and ongoing reporting of adverse events $[12,13])$ and economically. Regarding the economical issues, strong incentives in favour of choosing the less expensive generic versions (usually the non-branded drugs) have been implemented. It implies both higher margins for the pharmacies and avoidance of extra payments for the patients [3]. In this way, the Norwegian market of cheaper generics has developed substantially such that by 2009 as much as $70 \%$ of the defined daily doses in the generic interchangeable market were sold as cheaper generic versions [10].

In Pakistan, cheaper generic brands are available in the pharmacies and sold on average at half the price of their brand-name equivalents [7]. Ideally, these products should make it possible for the parts of the population who would otherwise be without treatment to receive affordable drugs. However, despite the lower prices, the patients as well as the health care providers are reluctant to use these drugs $[11,14,15]$. This may be due to the fact that generic manufacturers are not required to provide bioequivalence data and that there is a significant market for counterfeit products in the country $[16,17]$.

Despite the high number of Pakistani immigrants in Norway and the relatively long time that many of them have been residing in the country, studies of drug use in this population have not been identified. The research on generic substitution from Norway is restricted to the general population [18-20] (with about 10\% immigrants) and health professionals [21]. Despite the different scenarios regarding quality and safety measures between the countries, studies have demonstrated that Norwegian patients are also uneasy about generic substitution [18-21], and that it may influence drug adherence intentionally as well as unintentionally [18]. Moreover, several studies have shown that in order for generic substitution to be successful with regard to safe medicine use, information is a key factor [18, 22, 23]. This may be even more important among immigrants since they may in addition experience language barriers. It is not inconceivable that the accessibility of necessary information related to, for instance, drug use becomes more restricted. Furthermore, past experiences from their home country may elicit concerns about the quality of cheaper drugs, despite the new setting being a well-regulated health care system.

The aim of the present study was to explore how Pakistani immigrants on long-term drug treatment who live in Norway perceive generic substitution and to investigate how generic substitution influences drug adherence in this population.

\section{Materials and methods}

\section{Study population}

The study population consisted of 83 first-generation Pakistani immigrants living in Oslo, the capital city of Norway, or the surrounding area. The participants had to be chronic drug users on long-term therapy with antihypertensives, antidiabetics, and/or cholesterol-lowering drugs, and be in the age group $40-80$ years, since nonadherence is a well-known problem in this kind of patients [24].

\section{Recruitment}

The participants were recruited opportunistically in collaboration with two voluntary special interest groups (The International Health and Social Group and The Pakistani Woman Group), which work on strategies to improve integration of ethnic minorities. Information was provided during the networks' organised meetings for elderly immigrants (where the participants were mainly Pakistani) or at cafes where they gathered. In addition, other network members who fulfilled the inclusion criteria but were not present at any meetings were contacted by telephone by the network leaders.

All potential participants were given oral and/or written standardised information about the study in Norwegian and/or Urdu before they were asked to take part in the study. Those who were interested in taking part were put in contact with the interviewer and the time and setting for the interview was arranged. The response rate was $69 \%$.

\section{Study design}

The study design was explorative and based on personal face-to-face interviews using a semi-structured questionnaire. The questionnaire was originally developed for a previous Norwegian study that explored drug adherence following generic substitution in the general Norwegian population [18]. Based on experience with the questionnaire from the previous study, the questionnaire was modified in order to fit the target population, i.e. some questions were added (e.g. experiences from Pakistan with counterfeit drugs and drugs in general), more closed questions were followed by open-ended questions (i.e. to be more explorative), and more response options were added to some of the closed questions. Three quarters of the questions were open-ended or were followed by openended follow-up questions. Eleven questions dealt with drug adherence and attitudes towards drug use in general, including an estimation of how many doses they had 
intentionally and unintentionally missed taking during the last 14 days and whether or not they took drug holidays or in any other way used the drugs in ways other than the physician prescribed. Also, as part of the interview, all the participants had to tell and show which drugs they used at the time of the interview. Attitudes towards generic substitution constituted 17 questions and dealt with how the patients felt about substituting their $\operatorname{drug}(\mathrm{s})$ and their experiences with substitution. The patients were also asked to value the brand-name drugs compared with the generic alternatives in a simple willingness-to-pay exercise in order to unravel their attitudes towards generics from a different angle. The questionnaire was piloted before starting the study.

Each of the participants gave their informed consent (provided in Norwegian and Urdu) in writing. The study was approved by the Regional Committee for Medical and Health Research Ethics and the Norwegian Social Science Data Services.

\section{Data collection}

One interviewer conducted all the interviews during the period from October 2009 to February 2010, preferably in the informants' home. The interviews were conducted with an Urdu/Punjabi translator if this was found necessary from the pre-interview contact with the patient or his/her relatives.

\section{Data analysis}

The software SPSS (version 16.0) was used in the preparation of the data. The analyses were strictly descriptive. The answers to open-ended questions were coded and analysed categorically.

For all participants, a scale score of drug adherence was constructed by giving values to possible combinations of answers to the adherence questions $(1=$ often forgets and deliberately alters the recommended dose and takes/has taken multiple dosing of the same active ingredient, to $5=$ never forgets nor deliberately alters the recommended dose nor takes/has never taken multiple dosing of the same active ingredient). Based on these scores the participants were categorised as having poor (lower part of the scale) or good (upper part of the scale) adherence.

\section{Results}

Characteristics of the study population

The 83 long-term drug users who participated in the study had an average age of 57.8 years (range: $43-77$ ) and their mean length of residence in Norway was 29.3 years (range: 3-41). Eighty percent of the participants had some education, of whom $20 \%$ had higher education ( $>12$ years). Fifteen percent of the patients were actively employed. Sixty-five percent of the interviews were conducted with an Urdu or Punjabi translator since the participants were not fluent in Norwegian.

The participants had on average 3.4 diagnoses (range: 1-9) for which they were treated with drugs. In all, $76 \%, 67 \%$, and $51 \%$ used antihypertensives, antidiabetics, and/or cholesterol-lowering drugs respectively. The mean number of total prescription drugs was 6.7 (range: 1-28). Fifty percent of the participants claimed that they knew why it was advisable to treat their chronic condition(s) medically. Forty-seven percent reported that they had general concerns regarding medicine use, and 53\% were apprehensive about side-effects in particular. Further details of the study population -in relation to whether or not they had ever accepted generic substitution-are shown in Table 1.

Patients' perceptions of and experiences with generic substitution

Two thirds of the participants had always or sometimes accepted generic substitution in the pharmacy. Twenty-two percent said that they never accepted substitution, of whom nearly half had had their drugs substituted anyway without being aware of it. The remaining participants were unfamiliar with the problem as presented. In total, $73 \%$ of the participants were using non-branded drugs at the time of the interview. According to Table 1, generic substitution tended to be relatively more accepted in the younger age groups, among those with higher education, and among those who were sufficiently informed about both generic substitution and the drug therapy they were on. Language barriers and concerns about the drug therapy and particularly side-effects were relatively more prevalent among those who had accepted the substitution. The willingness to accept substitution increased with higher education. The reasons given for not accepting generic substitution are presented in Table 2.

One quarter of the participants were of the opinion that cheaper generic drugs were fake drugs. They used the term "no. 1" for brand-name drugs whereas "no. 2" alluded to counterfeit and non-branded drugs. In some cases different non-branded products were categorised as "no. 1" and "no. 2 " according to the order in which they were purchased. All of the participants were aware of the situation with counterfeit drugs in Pakistan as they had been informed by friends or the media, and $8 \%$ had experienced using these drugs in Pakistan themselves.

Of those who had accepted generic substitution, $41 \%$ were concerned when they started using the generically 
Table 1 Characteristics of the study population with respect to their generic substitution status (dichotomised as having ever or having never accepted substitution; $n=83$ )

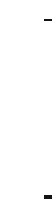

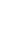

\section{Patients who accepted generic substitution}

n $\%$

Patients who refused generic substitution

$\bar{n} \%$

Sociodemographic characteristic

Gender

Female

Male

Age (years)

40-49

$50-59$

60-69

70-79

Educational level

None

Primary or secondary ( $\leq 12$ years)

Tertiary ( $>12$ years)

Length of residence in Norway (years)

$<10$

$10-19$

20-29

$\geq 30$

Fluent Norwegian speaker

Yes

No

Medical characteristic

Antihypertensive drug use

Yes

No

10

Antidiabetic drug use

Yes

Cholesterol-lowering drug use

Yes

Knowledge of the aim of the drug therapy

Yes

No

General concerns about medicine use

Yes

No

Concerns about side-effects

Yes

No

Received sufficient information

about generic substitution ${ }^{\mathrm{a}}$

Yes

No
30

24

11

23

16

4

(1)

7

35

12

26

44

36

18

30

24

32

22

29

25

34

20

58.8

75.0

68.8

67.6

64.0

50.0

41.2

66.0

92.3

0

75.0

54.2

70.0

51.9

89.7

69.8

50.0

64.3

66.7

71.4

58.8

76.2

53.7

74.4

74.4
56.8

82.9

47.6

29

15
21

8

41.2

25.0

31.2

32.4

36.0

50.0

58.8

34.0

7.7

100

25.0

45.8

30.0

48.1

10.3

30.2

50.0

35.7

33.3

28.6

41.5

23.8

46.3

25.6

43.2

17.1

52.4

22

14.7

$85.3 \quad 5$

10

60.0 
Table 2 Examples of the patients' reasons for refusing generic substitution ( $n=50$; multiple responses)

\begin{tabular}{ll}
\hline Reason for refusing generic substitution & $\begin{array}{l}\text { Number of } \\
\text { responses (\%) }\end{array}$ \\
\hline $\begin{array}{l}\text { Suspected the non-branded drugs of being fake } \\
\text { medications }\end{array}$ & $12(19.7)$ \\
"No. 1"/brand-name medication is the best & $10(14.8)$ \\
Used to the "no. 1"/brand-name drug & $9(14.8)$ \\
The physician should decide (since he/she knows & $9(14.8)$ \\
my body best) & $8(13.1)$ \\
Uncertain about the substitution in general & $4(6.6)$ \\
Fear/experience of side-effects & $3(4.9)$ \\
Cheaper medication is of poorer quality & $3(4.9)$ \\
Fear/experience of poorer effect & $2(3.3)$ \\
Felt better about the brand-name drug & $1(1.6)$ \\
Warning from family and friends & $1(1.6)$ \\
Distrust in drugs produced outside Norway &
\end{tabular}

substituted drug(s). After generic substitution, 26\% felt that the effect of the drug had changed, and all of these had experienced a poorer and/or slower effect (e.g. quote: "the no. 1 s work $100 \%$; the no. 2 s work $70 \%$ "). Twenty percent reported having experienced new or more side-effects. Of all the participants, $12 \%$ had a physician's exemption from generic substitution on the prescription because of a negative experience with the alternative product.

Table 3 shows that $46 \%$ of the participants were willing to pay something extra in addition to the basic copayment to avoid generic substitution. These participants were primarily those who reported a change in effect and/or those who had experience with fake medicines from Pakistan and were afraid the same could happen in Norway.

\section{Adherence to medical treatment}

A total of $46 \%$ of the participants thought it was difficult to remember to take their medication every day. During the previous 2 weeks, $31 \%$ said they had forgotten to take some of their medications about once a week while $11 \%$ said they forgot several times per week or even daily. Thirty-one percent reported that they had deliberately abstained from taking their medications from time to time, and $16 \%$ admitted that this had happened during the previous 2 weeks. Eighteen percent told that they occasionally took drug holidays. The main reasons for their intentional nonadherence were: side-effects, feeling healthy, travelling, running out of medication, and being dispensed nonbranded generics in the pharmacy. Of those who had had their drug(s) substituted in the pharmacy, $26 \%$ found it more demanding to keep track of their medication after the switch since they no longer knew their medication by name or appearance. It became difficult to recognise the drugs and know which drugs the new ones were replacing or for which purpose they were to be used. This was an extra challenge for those who were not literate or had poor eyesight. Fifty percent had noticed that the non-branded product had a different shape, size, or colour compared with the brand-name product they had received previously. Some commented on the convenience of a blister package over a box container since they were easier to carry with them and also more hygienic to use.

Trends in the results presented in Table 4 indicate that poor adherence was relatively more common among patients who were not fluent in Norwegian, among those who were generally concerned about medicine use and particularly side-effects, and among those who had accepted generic substitution in the pharmacy. Ten percent of the participants who were using generics were using two different products containing the same active ingredient, i.e. a branded and a non-branded drug, at the same time. These patients used several different drugs (3-13 drugs) and were, independently, patients who retrieved their medications from more than one pharmacy. At the same time they were among those who were unable to communicate with the pharmacy personnel either because they did not speak Norwegian or because they did not go to the pharmacy themselves. Some of them were not aware of the substitution in the first place and/or felt strongly against it.
Table 3 The amount the patients were willing to pay extra for the brand-name drug in relation to how they considered the copayment

a Converted from Norwegian
kroner
${ }^{\mathrm{b}} 38 \%$ of the retail price;
maximum $€ 230$ a year

\begin{tabular}{llcccr}
\hline & & \multicolumn{2}{c}{ The patients' consideration of the copayment } & \\
\cline { 3 - 5 } & & Inexpensive & Expensive & Don't know & Total \\
\hline Extra payment (in Euros ${ }^{\mathrm{a}}$ ) & 0 & 12 & 11 & 2 & 25 \\
& $0.1-6.5$ & 6 & 4 & 0 & 10 \\
& $6.5-26$ & 5 & 7 & 2 & 14 \\
& $26-65$ & 1 & 1 & 0 & 2 \\
& More than 65 & 3 & 8 & 1 & 12 \\
& Don't know & 4 & 12 & 4 & 20 \\
Total & 31 & 43 & 9 & 83 \\
\hline
\end{tabular}


Table 4 Distribution of adherence outcome in relation to possible explanatory variables $(n=83)$

${ }^{\mathrm{a}} n=59$

\begin{tabular}{|c|c|c|c|c|}
\hline & \multicolumn{2}{|c|}{ Poor adherence } & \multicolumn{2}{|c|}{ Good adherence } \\
\hline & $n$ & $\%$ & $n$ & $\%$ \\
\hline \multicolumn{5}{|l|}{ Sociodemographic characteristic } \\
\hline \multicolumn{5}{|l|}{ Gender } \\
\hline Female & 10 & 19.6 & 41 & 80.4 \\
\hline Male & 6 & 18.8 & 26 & 81.2 \\
\hline \multicolumn{5}{|l|}{ Age (years) } \\
\hline $40-49$ & 3 & 18.8 & 13 & 81.2 \\
\hline $50-59$ & 9 & 26.5 & 25 & 73.5 \\
\hline $60-69$ & 3 & 12.0 & 22 & 88.0 \\
\hline $70-79$ & 1 & 12.5 & 7 & 87.5 \\
\hline \multicolumn{5}{|l|}{ Educational level } \\
\hline None & 2 & 11.8 & 15 & 88.2 \\
\hline Primary or secondary ( $\leq 12$ years) & 12 & 22.6 & 41 & 77.4 \\
\hline Tertiary $(>12$ years $)$ & 2 & 15.4 & 11 & 84.6 \\
\hline \multicolumn{5}{|l|}{ Length of residence in Norway (years) } \\
\hline$<10$ & 0 & 0 & 1 & 100 \\
\hline $10-19$ & 1 & 12.5 & 7 & 87.5 \\
\hline $20-29$ & 4 & 16.7 & 20 & 83.3 \\
\hline$\geq 30$ & 11 & 22.0 & 39 & 78.0 \\
\hline \multicolumn{5}{|l|}{ Fluent Norwegian speaker } \\
\hline Yes & 7 & 13.0 & 47 & 87.0 \\
\hline No & 9 & 31.0 & 20 & 69.0 \\
\hline \multicolumn{5}{|l|}{ Medical characteristics } \\
\hline \multicolumn{5}{|l|}{ Number of prescription drugs } \\
\hline$\leq 7$ (average value or less) & 11 & 18.6 & 48 & 81.4 \\
\hline$>7$ (more than average value) & 5 & 20.8 & 19 & 79.2 \\
\hline \multicolumn{5}{|c|}{ Knowledge of the aim of the drug therapy } \\
\hline Yes & 7 & 16.7 & 35 & 83.3 \\
\hline No & 9 & 22.0 & 32 & 78.0 \\
\hline \multicolumn{5}{|l|}{ General concerns about medicine use } \\
\hline Yes & 11 & 28.2 & 28 & 71.8 \\
\hline No & 5 & 11.4 & 39 & 88.6 \\
\hline \multicolumn{5}{|l|}{ Concerns about side-effects } \\
\hline Yes & 12 & 29.3 & 29 & 70.7 \\
\hline No & 4 & 9.5 & 38 & 90.5 \\
\hline \multicolumn{5}{|l|}{$\begin{array}{l}\text { Received sufficient information } \\
\text { about generic substitution }{ }^{\mathrm{a}}\end{array}$} \\
\hline Yes & 11 & 32.4 & 23 & 67.6 \\
\hline No & 5 & 20.0 & 20 & 80.0 \\
\hline \multicolumn{5}{|c|}{ Accepted generic substitution in the pharmacy } \\
\hline Yes & 15 & 27.8 & 39 & 72.2 \\
\hline No & 1 & 3.4 & 28 & 96.6 \\
\hline
\end{tabular}

Information and knowledge about generic substitution

Generic substitution was known to $82 \%$ of the participants in the study. All of these had received some information about the substitution in the pharmacy except those who did not visit the pharmacy themselves and were informed to some degree by family members and/or friends. They had been told briefly that the drug they were being dispensed was a cheaper but equivalent version of the brand-name drug, which was produced by another firm. In addition, $43 \%$ had received some kind of information from their physician. Of the remaining, many expressed that they 
Fig. 1 The relationship between the number of patients and these patients' reasons for why the pharmacy personnel asked them to substitute their medicine(s) for generic ones $(n=83$; multiple responses)

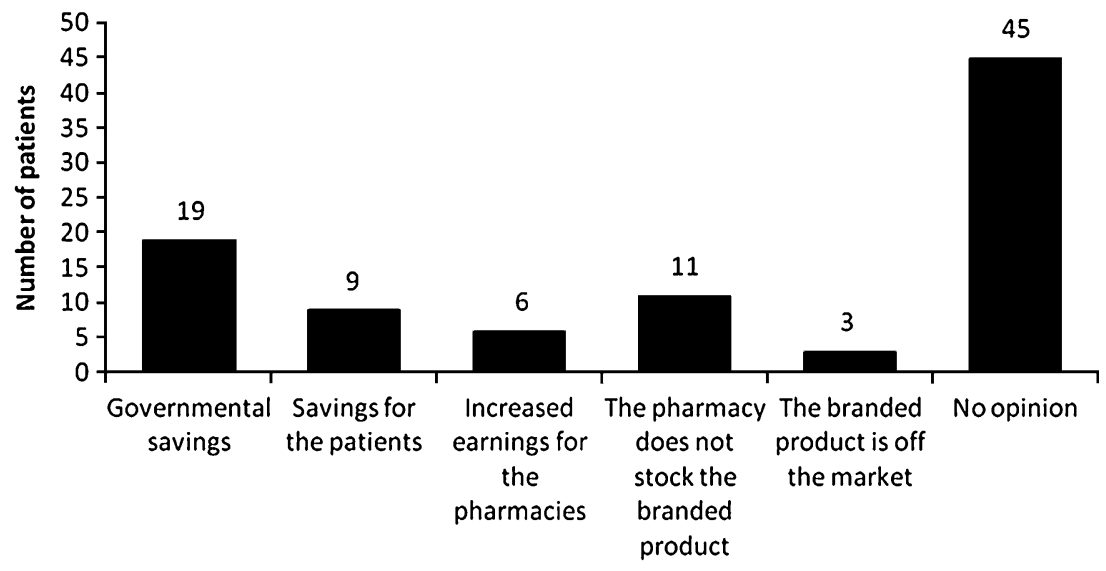

would have felt more positive and safe about generic substitution if their physician had given some information about the substitution or prescribed the version they obtained in the pharmacy. About half of those who reported having received information considered it to be sufficient for being able to feel safe about using the $\operatorname{drug}(\mathrm{s})$. The patients' perception of why the pharmacy personnel asked them to substitute their medicine(s) in the pharmacy are shown in Fig. 1.

\section{Discussion}

The present study explores how generic substitution is perceived by a population of Pakistani immigrants in Oslo, Norway. It is the second Norwegian study to show that generic substitution can be an additional challenge for drug adherence in patients on long-term therapies [18]. Both studies show that adherence may be affected intentionally as well as unintentionally because of concern and confusion regarding the new product. However, these results are most pronounced in the present study. Whereas $5 \%$ of the general population group unintentionally used more than one equivalent generic drug at the same time [18], the percentage among the Pakistani immigrants was twice as high. Furthermore, a considerably larger proportion of the Pakistani patients claimed that they had experienced a change in the effect or new or more side-effects. This mirrors the fact that they were also generally more concerned about substitution. Both studies show that the chance of erroneous drug use seems to increase for patients who are using more than one pharmacy for their drug purchases and for patients who are, for various reasons, not well informed about the intervention. In the present study, the patients who were erroneously using two equivalent generics at the same time were unable to communicate with the pharmacy personnel.

Insufficient information also tends to be a reason for having a negative attitude towards generic drugs. There was a clear association between non-branded generics and counterfeit products among the participants. Those who were unwilling to substitute their drugs generically reasoned that something that was cheaper could not have the same quality as more expensive products. A considerable proportion of the participants in this study perceived nonbranded drugs, often referred to as "no. 2s", as counterfeit drugs. A negative attitude towards generic substitution was reflected in the willingness to pay extra to avoid substitution even if they thought they had already paid enough in copayments. The patients' perception of high copayments may be explained by expectations of free services in a health care system based on high tax financing, of which the Norwegian one is an example [25]. Regarding patients experiencing language problems, it may seem a paradox that these patients were more prone to accept generic substitution; however, this may simply be because when asked about substitution in the pharmacy they responded without having understood or because they did not manage to articulate any response.

The participants in this study were recruited from the capital city of Norway since this is the region where by far the most Pakistani immigrants have settled [9]. The age range 40-80 years was selected in order to encompass a wide group of drug users with experience of how to cope with chronic conditions and, for many, multiple medications. The selected conditions (i.e. hypertension, diabetes, and hypercholesterolaemia), which are of high prevalence regardless of ethnicity, often carry with them the necessity for life-long drug therapy. Moreover, the drugs used to treat these conditions are primarily off-patent, and it is likely that most patients have been offered a cheaper generic alternative in the pharmacy. Regarding the representativity of the present study, it must be taken into account that the number of participants is relatively small. However, even this modest number of participants could only be recruited by involving special interest or network groups. It would have been by no means possible to have achieved a satisfying result without the help obtained from leading persons in 
Norway's Pakistani population. The fact that these people vouched for the reliability of the study conductors was key in the recruitment process, particularly as subjects had to allow the interviewer to take a look at their medication. For convenience therefore, the interviews were conducted in the participants' homes wherever possible.

The results from this study are not consistent with those from Dutch researchers van Wijk et al. [26]. Based on data from a prescription database, van Wijk et al. concluded that generic substitution of antihypertensive drugs did not result in lower adherence or more cardiovascular disease-related hospitalisations [26]. In both countries the pharmacy personnel are supposed to provide guidance in appropriate drug use; however, since Dutch patients usually register at a single pharmacy, it is conceivably easier to avoid erroneous drug use related to generic substitution. The different results may also be at least partially explained by the use of different methods. The present study made it feasible to discover problems that occurred on a personal level. These findings are not reflected in larger population-based datasets.

Patients may become insecure when questions about generic substitution are posed by the pharmacy personnel. As explored by for instance Waber et al. there is a significant association between reported effect and price regarding pharmaceutical products [27]. However, many patients accept non-branded generics if they had been approved or prescribed by their doctor [18, 28, 29]. In the case of first-generation immigrants, symmetric information from the different kinds of health professionals tends to be extremely important. The present study clearly demonstrates the importance of patient education, especially with regard to immigrants who may experience language as well as cultural barriers. Despite the moderate sample, it was possible to observe distinct differences in how generic substitution is perceived among Pakistani immigrants compared with the general Norwegian population [18].

\section{Conclusion}

This exploratory study shows that generic substitution may have a negative effect on drug adherence in Pakistani immigrants with chronic conditions living in Oslo (Norway). Concerns about the equality of the interchangeable drugs, experiences of change in effect or more side-effects, and confusion regarding counterfeit drugs made many patients apprehensive about using the cheaper generic alternatives. Also, because of confusion after substitution, 1 in 10 patients were simultaneously using two equivalent generics. These problems result primarily from inadequate knowledge caused by language barriers, but also from culturally conditioned views on encounters with the health care system.
Acknowledgements The authors are sincerely grateful to the International Health and Social Group and the Pakistani Woman Group who helped with the recruitment of patients. This study was supported financially for translator services by the Foundation for the Promotion of Pharmacy Practice (Norway).

\section{Conflict of interest None.}

Open Access This article is distributed under the terms of the Creative Commons Attribution Noncommercial License which permits any noncommercial use, distribution, and reproduction in any medium, provided the original author(s) and source are credited.

\section{References}

1. Garattini L, Tediosi F (2000) A comparative analysis of generics markets in five European countries. Health Policy 51:149-162

2. Haas JS, Phillips KA, Gerstenberger EP, Seger AC (2005) Potential savings from substituting generic drugs for brand-name drugs: medical expenditure panel survey, 1997-2000. Ann Intern Med 142:891-897

3. Håkonsen H, Horn AM, Toverud EL (2009) Price control as a strategy for pharmaceutical cost containment - what has been achieved in Norway in the period 1994-2004? Health Policy 90:277-285

4. Kanavos P, Mossialos E (1999) Outstanding regulatory aspects in the European pharmaceutical market. Pharmacoeconomics 15: 519-533

5. Simoens S (2008) Trends in generic prescribing and dispensing in Europe. Expert Rev Clin Pharmacol 1:497-503

6. McManus P, Birkett DJ, Dudley J, Stevens A (2001) Impact of the minimum pricing policy and introduction of brand (generic) substitution into the pharmaceutical benefits scheme in Australia. Pharmacoepidemiol Drug Saf 10:295-300

7. Mendis S, Fukino K, Cameron A, Laing R, Filipe Jr A, Khatib O, Leowski J, Ewen M (2007) The availability and affordability of selected essential medicines for chronic diseases in six low- and middle-income countries. Bull World Health Organ 85:279-288

8. World Health Organization (2004) The world medicines situation. WHO, Genova, WHO/EDM/PAR/2004.5

9. Statistics Norway. Population statistics. Immigrants and Norwegian-born to immigrant parents. 1 January 2009. A half million immigrants and Norwegian-born to immigrant parents. http://www.ssb.no/emner/02/01/10/innvbef/. Accessed 10 November 2010 [in Norwegian]

10. The Norwegian Association of Pharmaceutical Manufacturers (2010). Facts and figures 2010. http://www.lmi.no/dm_documents/ facts_and_figures_2010_powerpoint_ds5ok.ppt. Accessed 10 November 2010

11. Babar ZU, Jamshed S (2008) Social pharmacy strengthening clinical pharmacy: why pharmaceutical policy research is needed in Pakistan? Pharm World Sci 30:617-619

12. Madsen S, Nitteberg-Sørensen B, Harviken C, Samdal H, Roksvaag PO (2008) The generic list-a drug-political tool. Tidsskr Nor Legeforen 128:837-839 [in Norwegian]

13. Reppe LA, Stenberg-Nilsen H, Harg P, Hegge AB, Lillefloth AK, Buajordet I (2008) Adverse events related to substitution of generic products in Norway 2005. Tidsskr Nor Laegeforen 128:2696-2700 [in Norwegian]

14. Jamshed S, Hassali MAA, Ibrahim MIM, Babar ZU (2009) Knowledge, attitude and perception of consumers towards generic medicines in Karachi, Pakistan. Abstract PESP-11(000048). Malaysian J Pharm 1:14 
15. Kiani A, Qadeer A, Mirza Z, Khanum A, Tisocki K, Mustafa T (2006) Prices, availability and affordability of medicines in Pakistan. Report of the network for consumer protection, Islamabad http://www.haiweb.org/medicineprices/surveys/200407PK/ survey report.pdf. Accessed 10 November 2010

16. Business Monitor International (2009) Pakistan pharmaceuticals \& healthcare report Q1 2010. BMI's Industry Survey \& Forecasts Series, Business Monitor International, London

17. Kelesidis T, Kelesidis I, Rafailidis PI, Falagas ME (2007) Counterfeit or substandard antimicrobial drugs: a review of the scientific evidence. J Antimicrob Chemother 60:214-236

18. Håkonsen H, Eilertsen M, Borge H, Toverud EL (2009) Generic substitution: additional challenge for adherence in hypertensive patients? Curr Med Res Opin 25:2515-2521

19. Kjønniksen I, Lindbæk M, Granås AG (2006) Patients' attitudes towards and experiences of generic drug substitution in Norway. Pharm World Sci 28:284-289

20. Toverud EL, Røise AK, Hogstad G, Wabø I (2010) Norwegian patients on generic antihypertensive drugs: a qualitative study of their own experiences. Eur J Clin Pharmacol. doi:10.1007/s00228010-0935-x

21. Håkonsen H, Hopen HS, Abelsen L, Ek B, Toverud EL (2010) Generic substitution: a potential risk factor for medication errors in hospitals. Adv Ther 27:118-126
22. Hassali MAA, Shafie AA, Jamshed S, Ibrahim MIM, Awaisu A (2009) Consumers' views on generic medicines: a review of the literature. Int J Pharm Pract 17:79-88

23. Himmel W, Simmenroth-Nayda A, Niebling W, Ledig T, Jansen RD, Kochen MM, Gleiter CH, Hummers-Pradier E (2005) What do primary care patients think about generic drugs? Int J Clin Pharmacol Ther 43:472-479

24. World Health Organization (2003) Adherence to long-term therapies: evidence for action. WHO, Genova, ISBN 9241545992

25. Botten G, Aasland OG (2000) The public's expectations of the health services. Tidsskr Nor Laegeforen 120:2995-2999 [in Norwegian]

26. Van Wijk BL, Klungel OH, Heerdink ER, de Boer A (2006) Generic substitution of antihypertensive drugs: does it affect adherence? Ann Pharmacother 40:15-20

27. Waber RL, Shiv B, Carmon Z, Ariely D (2008) Commercial features of placebo and therapeutic efficacy. JAMA 299:1016-1017

28. Shrank WH, Cadarette SM, Cox E, Fischer MA, Mehta J, Brookhart AM, Avorn J, Choudhry NK (2009) Is there a relationship between patient beliefs or communication about generic drugs and medication utilization? Med Care 47:319-325

29. Vallès JA, Barreiro M, Cereza G, Ferro JJ, Martínez MJ, Escribà JM, Iglesias B, Cucurull E, Barceló E (2003) A prospective multicenter study of the effect of patient education on acceptability of generic prescribing in general practice. Health Policy 65:269-275 